
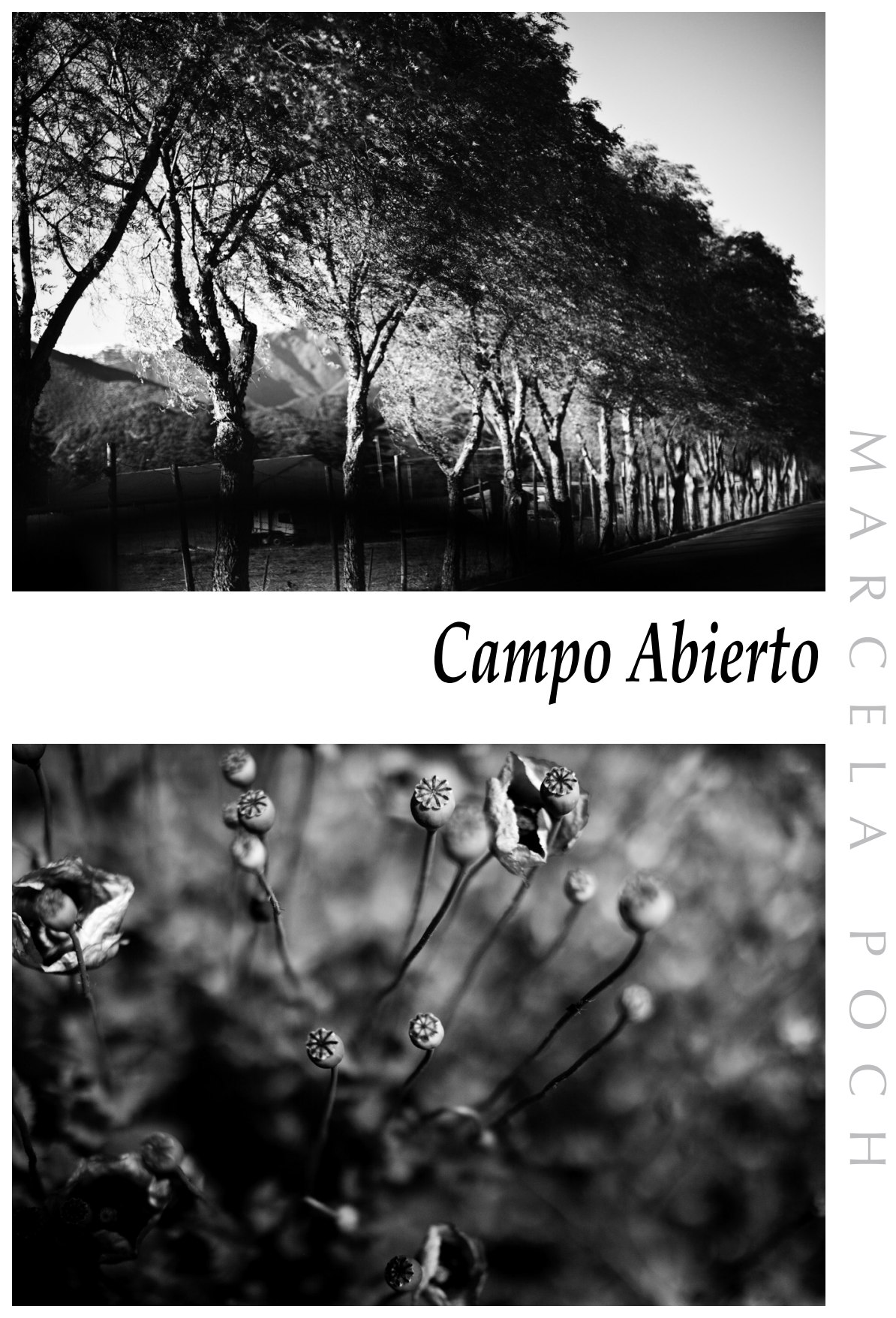
REVISTA NOMADÍAS

Julio 2011, Número 13, 85 - 101

\title{
Homenaje a Isidora Aguirre (1919-2011): el tapiz de un encuentro
}

\author{
Andrea Jeftanovic \\ Universidad de Santiago de Chile \\ ajefta@yahoo.es
}

Durante dos años visité a Isidora Aguirre en su casa de la calle Rengo, en la comuna de Nuñoa. Llegaba a las cuatro de la tarde, otras veces a almorzar, para pasar juntas una tarde de conversaciones. Aunque viviésemos en la misma ciudad, ir a estas sesiones era para mí un viaje; cruzar el umbral de su puerta era semejante a cruzar una frontera. Ya adentro, el tiempo transcurría pausado y elástico entre las claves del tejido microscópico de los inicios del teatro en Chile, de las mujeres artistas en los años cuarenta, por un París de posguerra con una bohemia inquieta, o bien la Cuba revolucionaria con la floreciente Casa de las Américas, la campaña de Allende. Fue un recorrido por los caminos de la creación, del compromiso político, del trabajo con el naciente teatro chileno, de la efervescencia cultural del Chile en los sesenta, de las tensiones en el medio, del éxito, de la experiencia del arte, el reconocimiento en el extranjero y los constantes viajes, la resistencia durante la dictadura y la cooperación en la vida clandestina, la dificultad de montar nuevas obras en los años noventa. Y, también, fue un honesto recorrido por esos trayectos pedestres y cotidianos de las dificultades económicas, de la conciliación entre el trabajo teatral y la crianza de los hijos, de las rupturas amorosas, de la pérdida de amigos. Isidora, generosa en su relato, me hizo partícipe de su imaginario, de sus experiencias de vida, de sus procesos escriturales, de los cruces entre biografía y creación.

No me acerqué a Isidora pensando en hacer un libro sobre su vida y obra. Acudí a ella aún sin conocerla, porque me encontraba participando en un proyecto de intercambio de escritores, 
Entresures, en el que, como anfitriona en Chile, debía escoger un artista de trayectoria con quien trabajaríamos con mis "huéspedes" literarios: la escritora nicaragüense Eunice Shade y el sociólogo colombiano Gabriel Restrepo. Finalizado ese proyecto, la palabra de Isidora quedó sonando y quise prolongar ese encuentro, tomar la hebra de ese lazo real y llevarlo lejos, a un lugar donde pudiera acceder al núcleo de esta creadora y reconstruir su trayectoria. Creo que en un comienzo inventé algunos encuentros con diversas excusas para satisfacer el simple placer de seguir escuchándola. Isidora genera cierta adicción, "enamora" (y eso lo dicen cuantos han trabajado con ella) por su sentido del humor, su mente abierta, sus anécdotas, su visión de la vida, su cariño, su espontaneidad. Pero todos estos atributos personales se hacen más relevantes cuando se anudan en una artista excepcional y, para ser precisos, en la dramaturga más notable de Chile y seguramente de Latinoamérica, a la altura de Sabina Berman en México, Griselda Gambaro en Argentina, Josefina Plá en Paraguay. Imposible resultaría, a esta altura del siglo XXI, hacer un recuento de la dramaturgia latinoamericana sin que figure su nombre.

Isidora fue una precursora en el campo de los textos teatrales y las tablas. Si trazamos la historia del teatro nacional, su figura la atraviesa de principio a fin: tanto por su extensa obra como por su longevidad, coincide con el surgimiento del teatro y su consolidación, cuando nacen las primeras compañías y toman fuerza los teatros universitarios. Se inicia en el oficio en 1954, cuando se estrenó su primer texto; hasta hace poco seguía escribiendo, y sus textos continúan siendo montados en Chile y en el extranjero. Hasta la fecha ha escrito cuarenta obras teatrales, cuatro novelas (una aún sin publicar), radioteatros, monólogos radiales, libretos para televisión y variados textos de literatura infantil. Pero no es sólo el extenso número de obras lo que llama la atención, sino también la variedad de sus registros. Ha escrito teatro de carácter social y político con obras como Retrato de Yumbel, Los papeleros, Los que van quedando en el camino, la popular La pérgola de las flores. Fue vanguardista al repensar figuras históricas y cruzarlas con el presente, en piezas como Lautaro, Manuel Rodríguez, Diego de Almagro, Los libertadores Bolívar y Miranda, Diálogos de fin de siglo (sobre el presidente Balmaceda). Y trabajó textos más intimistas, en los que indaga problemáticas de género o de pareja, como lo hizo en Pacto de medianoche, Carolina, La dama del canasto, Maggi ante el espejo, Esta difícil condición y Las Pascualas. También utiliza diversas aproximaciones a sus temas 
y personajes, que alterna entre sus producciones o al interior de una misma obra: estéticas realistas se mezclan con elementos del mito y del folclore, canciones y coreografía, discursos políticos con humor popular, escritura clásica con expresiones locales. Por otra parte, desarrolló una línea importante de teatro infantil, como la conocida Don Anacleto Avaro y adaptaciones de tragedias clásicas para escolares.

Y junto con estas múltiples entradas a la producción dramática, Isidora Aguirre es ella misma, en cuanto creadora, un ser multifacético, alguien que conoce y diferentes ramas del arte. Se inició como escritora e ilustradora de libros para niños. Estudia técnica fílmica en Francia, dramaturgia en la Academia del Ministerio de Educación que dirigía Hugo Miller. Fue profesora de Teatro Chileno y de Construcción Dramática en la Escuela de Teatro de la Universidad de Chile; también impartió clases en la Universidad Técnica del Estado, hoy Universidad de Santiago, entre 1970 y 1973, y enseñó en academias privadas y talleres, en provincias de nuestro país y en otros lugares de Latinoamérica. Sin embargo, diría que no es esta episódica formación la que explica su obra, sino más bien un cúmulo de experiencias vitales, junto a un ejercicio autodidacta por parte de una mente inquieta, sensible, imaginativa y rigurosa, que tuvo el privilegio y el interés por experimentar la música, la danza, la pintura, las artes manuales.

También fue una narradora de tomo y lomo. Lo ratifican sus cuatro novelas publicadas y las dos inéditas que dejó, en las que combina la memoria y la evocación fantasiosa, la biografía y la historia. En este género también habría que mencionar su temprana incursión en literatura infantil, con cuentos y textos Ocho cuentos y Wai Kii. En narrativa su vigencia es incuestionable, pese a que se la conoce principalmente como dramaturga. En 1987 publicó Doy por vivido todo lo soñado en Plaza \& Janés, que pronto logró segunda edición. Luego la misma editorial catalana publicó Cartas a Roque Dalton en 1990. En 1998 se publicó Santiago de diciembre a diciembre en LOM Ediciones y en la editorial vasca Xlaparta. En el 2007, Uqbar Editores, a cargo de Isabel Buzeta, reeditó Confieso..., para al año siguiente publicar su novela Balmaceda, diálogos de amor y guerra. Por otra parte, editorial ZigZag lanzó el mismo año una colección de cuatro cuentos infantiles titulada La chacra de don Candelario. En 2008, Sangría editores, a cargo del escritor y editor Carlos Labbé, reeditó Cartas a Roque Dalton.

En su vasta producción teatral generó una poética de la 
realidad. Isidora Aguirre, cuando escribía, siempre partía de la realidad. La inspiración brotaba de esa fuente directa, lo que ella llamaba "rescatar" episodios y personajes de nuestra historia o de la cotidianeidad. Así me transmitió ella una máxima de su poética: "Siempre pienso que mis obras, si retratan bien a la realidad —como decía Chejov- retratan también al ser humano y, por eso, son universales". Es así como, en la mayoría de sus obras, hace confluir la documentación, la historia, la antropología y los testimonios orales. En este sentido, era una dramaturga estudiosa que se documentaba con rigor: en el terreno mismo, indagaba, tomaba notas, preguntaba, dialogaba, usando métodos diferentes en cada caso, "sacando el hilo por la puntita", como ella decía para referirse a las preguntas indirectas. Tenía una especial facilidad para reproducir diálogos, las hablas populares, las expresiones genuinas, los dichos de diversas épocas, a los que llega documentándose en terreno o en sus investigaciones bibliográficas. Así como entraba en la psicología de sus personajes, entraba en el modo cómo se expresan; es capaz de recrear el vocabulario y la gramática de la Conquista en el siglo XVI o de un pueblo aislado en la precordillera en 1970. Atraviesa la historia con las palabras, para extraer nuevos significados que nos ayuden a descifrar nuestro presente. Veo en su escritura la capacidad de desentrañar la condición humana, tanto en el sufrimiento como en la crítica y el humor.

El libro que hicimos juntas, Conversaciones con Isidora Agui$r r e^{1}$, es un libro que trasciende una vida singular, pues si bien se propone recorrer el vasto itinerario de Isidora como dramaturga, escritora y mujer de la cultura, es también una invitación a recorrer las transformaciones, desarrollo y profesionalización del teatro nacional y del lugar que ha ocupado la mujer en él. $\mathrm{Y}$, al mismo tiempo, quiere ser un bosquejo de ciertos procesos históricos y culturales que van desde mediados del siglo pasado a hoy. Porque Isidora, atenta y sensible a su entorno, trazó en este relato vivencial y en la práctica de las tablas las problemáticas del continente, de nuestra sociedad y del género humano. No es menor provocar, en el contexto del bicentenario, un diálogo con una mujer creadora, vanguardista, cuya obra y experiencias de vida ayudan a comprender los cambios, continuidades y tensiones del teatro y de la sociedad chilena y latinoamericana.

No recuerdo la fecha exacta. Solo sé que un día fui a su casa con una grabadora, lamentando todo lo que no había registrado técnicamente en las reuniones anteriores, y le propuse hacer un libro; sí, un libro que registrara su experiencia vital y artística. 
A partir de ese momento, la tecla Play funcionó por más de dos años.

Siempre me pareció que debía ser un libro que trabajara desde la conversación, y no un ensayo o un volumen de memorias sobre Isidora, pues nada mejor que el testimonio vivaz de esta singular entrevistada, que desborda vida y genialidad, y también la selección en conjunto de sus registros personales (diarios, cartas, apuntes de trabajo, crítica de la época) para integrar contenidos. Isidora tuvo, así, un rol activo en el proyecto, no el de mera entrevistada. Su historia iba irrumpiendo en su mente, en mi memoria. Tanto así, que muchas veces, al escribir, me sentí como ventrílocua que daba voz a una historia que no había vivido, pero que de pronto me brotaba como propia. Toda conversación supone un hablante capaz de descifrar a un oyente, pero en nuestro diálogo solían confundirse las hablas y las escuchas: de repente me encontraba siendo capaz de completar sus frases, reconstruir sus anécdotas, o bien escuchar resonancias emotivas de esta genealogía personal.

Esta larga conversación también tuvo un valor terapéutico, tanto para Isidora como para mí, en distintos sentidos. Ella me confesó en la etapa final que, durante este tiempo, se había hecho patentes sus mecanismos de escritura, muchas veces intuitivos e inconscientes; que ahora visualizaba decisiones y procesos creativos que antes eran puntos ciegos. También que en la revisión de su vida había comprendido la importancia de determinadas experiencias y personas, y logrado jerarquizar, distinguir, apreciar diversas circunstancias y encuentros. $\mathrm{O}$ bien comprendió algunos episodios vitales en esa lógica de causa y efecto, de origen y destino. Creo que a veces fui testigo de esas revelaciones, cuando una pregunta que parecía irrelevante o descontextualizada despertaba un relato poderoso, caótico, inédito. A veces su propio relato generaba una sorpresa, un descubrimiento. También pude observar la añoranza que despertaba en ella el contarme anécdotas que animaron su oficio y su vida, porque le hacían revivir cuánto disfrutó trabajando en determinada obra, o viviendo una específica relación personal. Nombres y lugares me iban siendo familiares y poblando ese universo recreado de una memoria casi compartida. Un testimonio directo tiene esa ventaja: que, junto con la información que se te entrega, de alguna forma te contactas con la corriente emocional de quien habla. Al mismo tiempo, yo iba grabando las conversaciones y armando el libro a medida que iba forjando mi espacio en la literatura, experimentando desde un incipiente lugar algunas de las difi- 
cultades en el quehacer creativo de las que hablaba Isidora, el esfuerzo por compatibilizar trabajo y crianza de los hijos, ciertas resistencias a la escritura de la mujer, el largo camino que supone un texto. Siempre salía de las sesiones llena de energía, con ganas de escribir, de hacer cosas, de vencer obstáculos.

Isidora participó en este proyecto con disciplina, como una alumna aplicada. Durante las sesiones hacía un despliegue de materiales que complementaban su relato de vida, o bien leía en voz alta algún fragmento pertinente, buceaba en su computador hasta hallar imágenes, textos inéditos. Nunca la vi fatigada por las extensas sesiones de entrevistas; me superaba en energía cuando a veces, entrada la noche, yo me retiraba y ella me anunciaba que a continuación retomaría algún texto que estaba revisando. La noche es su territorio: sé que se quedaba trabajando hasta las tres de la madrugada. Esa disciplina y capacidad de trabajo me daban indicios de la energía que pudo guiar la escritura de cuarenta obras de teatro y cuatro novelas en medio de otros trabajos y la crianza de cuatro hijos. Tanto en el testimonio oral como en la revisión y edición de las entrevistas, se comprometió por completo, entendiendo la importancia de este libro: el repaso y registro de toda una vida dedicada al teatro y al arte; el registro de $s u$ vida. Porque la transcripción de las entrevistas daba origen a extensos archivos que yo ordenaba por temas, cronologías, más que nada en un intento de establecer una ruta de navegación, la cual diseñé después de leer casi toda su obra dramática y narrativa, como también las principales referencias críticas. Siempre había un texto escondido que era una sorpresa para mí; obras por encargo, café-concerts, monólogos, adaptaciones. Así, el mapa que yo trazaba para avanzar entre la avalancha de información, siempre adquiría formas rizomáticas. Isidora se me escapaba una y otra vez, cuando yo intentaba amarrar esas caudalosas experiencias en alguna categoría, que siempre me parecían forzadas, azarosas; un caprichoso intento por establecer un orden para dejar fluir experiencias y reflexiones en una lógica de temas y momentos. Luego, esos textos llegaban a las manos de Isidora, que corregía sus decires, muy crítica a su expresión oral ("escribo mucho mejor de lo que hablo"), y así se complementaba "lo dicho" con "lo escrito". A su vez, revisábamos en conjunto sus diarios de vida, cartas personales, documentos de investigación de las obras, para seleccionar fragmentos que enriquecieran el rompecabezas de su testimonio, como estos que comparto ahora en un esfuerzo de síntesis: 
Fragmentos de diarios de vida de Isidora Aguirre²; las contradicciones de una mujer creadora

"Y empezó esa 'cosa'. Desde entonces vivo siempre alerta."

10 de mayo, 1945

Tener que seguir siempre alerta cuando es tan tentador dormir. Con el deseo de ser de pronto sólo como una más de aquellas personas anónimas que llenan las calles y que han de tener pequeñas metas diarias que cumplir. Alguien sin tantas dudas y tantas preguntas sin respuestas. En un tramo de mi vida, me dormí durante cuatro años y siempre había sol, bebés, una acequia al final del parrón, con más zancudos que peces, y una lagartija reina con su coronita en la frente, dormida al sol sobre una piedra. Había tiempo para estudiar a esa lagartija, para saborear las uvas en la viña, para salir en las tardes a "cazar" los espárragos que sólo asoman su puntita y echarlos a la olla en una cocina a leña. Tiempo para escuchar el zumbido de los insectos. El sopor, la paz (mi barriga con una nueva vida formándose). Todo era sencillo y éramos felices Gerardo y yo. O creíamos que la felicidad era eso, el matrimonio, un bebé por venir, otro en la cuna, mutuo apoyo, la seguridad algo que se anunciaba como permanente. Y empezó esa "cosa". Poco a poco. Primero, una leve irritación, luego la inquietud que nos roe por dentro, la misma de la adolescencia cuando sentía el impulso de hacer algo, sin saber qué, y la paz fue perturbada. Desde entonces vivo siempre alerta.

\section{PARís, 2 de agosto, 1948}

Aquí estoy, preguntándome si debo escribir para re-encontrar lo vivido, cuando este cuarto del Hotel Mont-Thabor sea algo muy alejado en el tiempo. Imposible describir el cúmulo de sensaciones del viaje hasta París al contemplar nuestro mapamundi desde arriba. La vista se regocija con las blancuras de los Andes, los picachos nevados. El espectáculo dura lo justo para enterarnos de que esa cordillera que vemos a diario al final de una calle no es puro perfil, que entre sus cimas hay una ancha cuna donde nacen los ríos. Sigue la pampa interminable, plana, lisa, indefensa ante el sol, cortada en cuadraditos verdes con un ojo de luz al centro, el pozo de agua para el ganado. Nuestra Señora de Luján se alza en esas soledades, proyectando una sombra oblicua. Mi primer viaje en avión: sola por los aires, sin preocupaciones ni 
responsabilidades, la paz después de unos muy días agitados. Soy perfectamente feliz. El runrunear de los motores me acompaña.

Por las noches, el Café Flore, el rendez-vous bohemio con el amigo de Gerardo dueño del Tabú, cave existencialista, luego de cenar en Les Deux Canettes. Todo se encuentra en esas tres cuadras del bulevar Saint Germain. El existencialismo sigue vigente, sin Sartre ni la Beauvoir, sólo con la exótica Gréco y sus canciones. La iglesia, bellísima, nos grita su antigüedad. Frecuentan el barrio los artistas, cineastas, un actor de Roma, ciudad abierta. No pierdo la esperanza de ver a Gérard Philipe, que admiré en las películas Le diable au corp, La chartreuse de Parme, El príncipe idiota, el más atractivo de los actores jóvenes. La bella Simone Signoret entra y sale del Flore. En el Club Saint Germain, filas en la puerta esperando entrar, sorda pulsación del jazz. Por una escala de madera rústica se baja a la cave, pequeña bodega, última moda. El aire se puede desplazar con la mano. Gente pintoresca, pelo largo, camisa a cuadros. Bailan el boogie-woogie.

\section{PARÍs, 10 de marzo, 1949}

La IDHEC (Escuela de Cine) me absorbe por completo, hay días en que las clases no dejan tiempo para almorzar. Hablo, sin darme cuenta, en la jerga de cine: veo en gros plan, o me acerco en travelling, oigo voces en off. Cuando Gerardo, chacoteando, me tiró al suelo, sólo atiné a decir "te veo en contre-plongé...". Uno de los alumnos, gran admirador de Breton (el que es muy discutido), habla ceceando, mechas tiesas, ojos dulces. En clase de estudio del guión, le gritó, impaciente, al profesor que iba muy lento en el pizarrón: "Et là, je fais un gros plan d'un 'zexze' de femme, criant 'Ze' t'aime!" ("Y ahí, hago un close-up de un 'sexo' de mujer, gritando 'te amo'").

\section{1 de abril, 1954}

Repaso mi estado de ánimo de este año: fuerza, entusiasmo, vitalidad, muchas interrogantes, temor a no saber resolver nada, eterna búsqueda. Presentir, sin embargo, que hay algo grande que está ahí, difícil de alcanzar pero que, de algún modo, nos aguarda. El equilibrio perdido que, sólo al caminar por las calles de París, se me fue infiltrando poros adentro (¿la armonía arquitectónica de la ciudad y al equilibrio del espíritu francés?).

Tengo mucho trabajo, las traducciones con que mantengo la casa desde que nos separamos con Gerardo. Pasé a ser marido 
de mí misma, padre y madre de las hijas. Para escribir teatro le robo tiempo al tiempo. Con tesón y paciencia, trato de realizarlo en la mejor forma.

\section{ESCUELA DE HUGO MILLER, 6 de mayo, 1951}

Ahora sí, siento que puedo realizar algo. Ayer me inscribí en el curso de Arte Dramático y Técnica del Drama en la Academia de Hugo Miller. Se equivoca José Ricardo en lo de "se nace con esa disposición, ¡o nada!". (Lo reivindico porque, poco antes de mi viaje a París, su obra Bárbara Fidele, que le escuché leer, me impactó de tal manera que fue mi primer impulso para escoger el teatro en la escritura.) La técnica se puede estudiar. Con instinto y con imaginación se escribe, si hay talento. Luego, con el estudio de la técnica, la razón analiza y corrige lo que el instinto propone.

Los últimos días del mes de marzo me dejaron esa depresión que atribuyo al otoño. Pero con el año organizado, estoy bien. Tendré que dejar mis clases de dibujo, y lo siento: mi profesor, Vittorio di Girólamo, expuso uno de mis dibujos a lápiz: "Amo tu jarrón", me dice. Pero al preguntarle, "¿qué crees que debo elegir?", respondió, sin vacilar: "El teatro es lo tuyo". Regalé lápices y colores.

\section{1 de mayo, 1951}

Tengo ahora horario completo. Debo seguir el curso de Actuación. ¡Al fin voy a conocer el teatro desde dentro, como tanto lo deseaba! ¡Más vale tarde que nunca! Lo digo porque a fines del año pasado, Vittorio me pidió que fuera su ayudante de dirección en una obra de la Universidad Católica (Las nubes, de Aristófanes), que debía presentar "a media confección" para ser o no aprobada ante la directiva del Teatro. ¡Esa experiencia terminó mal! Teníamos excelentes actores, como Jorge Álvarez y Jaime Celedón, pero no era bueno el del personaje que dialogaba con Carlos Lazo, con el rol del "Razonamiento Justo". Durante la presentación, Vittorio, molesto por lo mal que leía, me ordenó: "Acércate, pídele el libreto y sigue leyendo tú", lo que debió resultar bastante insólito para los del jurado. Al finalizar el ensayo, antes de que ellos se pronunciaran, Vittorio se levantó y declaró, enfático: “Esto es una porquería!". No hubo comentarios del jurado, se acabó mi experiencia. Fui a ver una película sacadora de lágrimas, para llorar a mis anchas. 
30 de agosto, 1951

Entre los diálogos que me pide Hugo para aplicar los preceptos de Stanislavsky, escribí uno basado en una acalorada discusión con Gerardo. Llegó una noche, vísperas de Navidad, después de estar ausente unos días, como suele hacerlo (ya las cosas no andan bien), trayéndome de regalo de Pascua un monedero de piel de ternera, con un billete de cinco mil pesos. Deudas de arriendo del departamento, colegio de las niñas, superaban los cinco mil. Le reproché no haberme dado antes el dinero. En suma, no me alegré como él esperaba, eso le molestó y discutimos, pelea conyugal... Le eché en cara su irresponsabilidad y poco a poco la discusión subió de tono hasta que terminé, cual esposa frustrada, llorando silenciosamente bajo las sábanas para hacerlo sentir culpable. Gerardo, frente a la ventana abierta de la noche veraniega, me pregunta: “¿Qué quieres que haga con este regalo?". No hubo respuesta. “Lo lanzo por la ventana?”. Y yo, picada: "Como quieras". Lanzó el monedero, con el impulso de proyectarlo lejos, y partió. Cuando se fue, ya avanzada la noche, tomé una píldora para dormir un poco, ya que debíamos ir temprano a una población a repartir juguetes. Le pedí a la niñera que me despertara al aclarar, con la esperanza de ver dónde había caído el monedero con los cinco mil pesos. ¡Bendije mi suerte al verlo relucir al sol! Había caído en el techo de la casucha del cuidador del sitio que se ve desde mi ventana. Envié a la niñera a rescatarlo. Desde la ventana pude ver cómo el hombre subió por una escala y, sin abrirlo, se lo pasó. ¡Salvada! Como tenía que escribir un diálogo para el postulado de Stanislavsky —acción directa— relaté la experiencia con poca elaboración, casi igual a lo ocurrido. Sólo modifiqué lo que parecería poco creíble: lanzar un dinero del que se tiene urgencia por la ventana, un gesto de caballero español que no sería comprendido. Así es que lo que él lanza en mi diálogo es un sobre del que antes ha escamoteado el dinero. Lo insólito para mí fue escuchar, entrando a la Academia, a tres parejas de actores peleándose a gritos con las mismas frases con que discutíamos con Gerardo. Extraña sensación. ¡Mi primera experiencia como dramaturga!

PARIS, 10 de mayo, 1967

Ionesco: "Yo, señorita, parto cada día hacia un lugar diferente, pero no llego nunca a ninguna parte..."

Conocí a Ionesco en París, a fines del año 1967, de regreso del Festival Internacional de Teatro en La Habana. Un ex compañero 
de la escuela de cine, que entonces era director de TV, me llevó a ver una obra de teatro que debía filmar (El juego de la verdad y la mentira), donde actuaba el entonces muy popular François Perrier. Vimos con mi amigo la primera parte desde el camión de la Televisión, luego entramos a la sala de teatro, a medio vaciar por el intermedio. En un palco estaba Ionesco con su esposa. Me preguntó mi amigo si deseaba ser presentada. No hubiera aceptado de no tener una pregunta que hacerle; Ionesco era el principal invitado al Festival en La Habana y había sido muy notoria su ausencia, y cuando le preguntaron a una francesa, la secretaria de J. L. Barrault, si sabía por qué no había llegado, sin vacilar repuso (en francés): "Seguramente está bebiendo whisky en Canadá y se olvidó". Me llevó mi amigo hasta el palco; al presentarme, él y su mujer me saludaron amablemente, me invitaron a tomar asiento y quedarme para ver la segunda parte de la obra con ellos. Le comenté a Ionesco que venía del Festival de La Habana y que todos se preguntaban por qué él no se había presentado. En forma ionesquiana repuso con la misma, idéntica frase de Mlle. Benmusat: "Ah, Mademoiselle, je buvais du whisky à Canada et j'ai oublié...".

Al llegar a la puerta del teatro, ya en la calle, me preguntó qué tenía que hacer o adónde iba. Veía al frente un bar iluminado, y tenía la seguridad de que Ionesco cruzaría la calle para esperar ahí a su mujer. Por la forma en que me hizo la pregunta, había la posibilidad de insinuar que no tenía nada que hacer, pero por discreción, ya que no me estaba invitando, le mentí: "Me espera mi amigo en el camión de la TV". Quedé muy defraudada. Pero tuve una compensación: al poco tiempo, Ionesco y su mujer llegaron a Chile invitados y me ofrecí, como solía hacerlo con invitados del Teatro, para acompañarlos como intérprete. Logré, entonces, como se dice en criollo, "sacarme las ganas". Ionesco y su mujer, al igual que en París, me trataban en forma amistosa, casi — diría - como a una antigua conocida. Creo que se sentían bien al tenerme siempre cerca en las charlas, visitas o entrevistas.

26 de diciembre, 1985. CARTA A MICAELA - DIARIO A UNA NIETA RECIÉN NACIDA

Querida Micaela, ¿quieres saber lo que significa la creación para mí? La periodista Marcelle Auclaire, citando a García Lorca, se pregunta: "¿Para qué existen los poetas si no es para decir con belleza lo que sentimos?". Es el regalo que nos hacen: enseñarnos a ver, a descubrir, a nombrar con magia las cosas, a entender 
lo que tenemos aún sin formular. Dice García Lorca: “Cuando termino un trabajo y siento el orgullo por haber creado algo, no pienso en el mérito personal: soy como un padre cuyo hijo es hermoso. Después de todo, es un don del azar". Lo menciono porque en Retablo de Yumbel estoy en la etapa que más me agrada, el pulido. Lo difícil es estructurar la obra, tanteando, ver hacia dónde te llevan los personajes, dudando, cortando. Es la parte en la que "suda el artesano". Pero con la obra hecha, es una delicia corregir, lo que tiene que ver con el oficio aprendido (el talento no se aprende, se cultiva). Muchos aspirantes a autores sólo con talento, escriben llevados por la inspiración; pero si no tienen el oficio, sus obras suelen resultar poco atractivas. Y en el oficio hay grandes dosis de paciencia. Lo comento porque hay en tu mirada una lucidez, una inteligencia precoz que no había visto en recién nacidos; quizá vas a ser escritora. Una vocación fuerte, como la mía, tiene problemas y compensaciones. No sé vivir sin estar escribiendo o trabajando en el montaje de una obra. Escribí con mucho esfuerzo mi comedia musical, La pérgola de las flores, basándome en mis conocimientos de técnica. En cambio, otras obras las escribí con la inspiración. En Lautaro dejaba actuar el instinto, lo emocional. Curiosamente, La pérgola de las flores ha sido lejos la más apreciada. Mientras la escribía, ¡lo último que imaginé es que me daría más fama y dinero que lo que se suele obtener con el teatro!

\section{1 de septiembre, 1986}

El mes pasado se estrenó Retablo de Yumbel. Fue emocionante. Las mujeres parientes, madres, hermanas, hijas, esposas de los 18 mártires que nombro al final, estaban en el teatro. Me abrazaban llorando, dándome las gracias por nombrarlos. El estreno fue en Concepción, y la tercera función de la obra coincidió con el atentado a Pinochet organizado por los del Frente Patriótico Manuel Rodríguez. Como le había pedido en la manda a San Sebastián que, además de escribirme la obra, me sacara a Pinochet para que la pudieran dar sin peligro, fue como si me dijera "lo intenté, le dimos un susto, pero no podía matarlo..." Lo del atentado fue una escena de guerra, un tiroteo de igual a igual con los que defendían a Pinochet; desgraciadamente murieron unos de su escolta. A él lo sacaron a tiempo. Digo "escena de guerra", porque unos jóvenes, según un plan que fraguaron a riesgo de sus vidas para terminar con la dictadura (a uno le habían asesinado a su padre), se enfrentaron a los de la escolta, hombres 
bien entrenados. Aunque no estoy de acuerdo con estos actos de violencia, es diferente de cómo operan los del gobierno: ellos fusilan a los que han tomado presos, que no pueden defenderse y que no han cometido ningún delito. Además, ocultan sus cuerpos. Y así de cobarde ha sido la venganza: mataron a tres personas, a cambio de los escoltas muertos, gente que no participó en el atentado, entre ellos a un periodista muy estimado y a quién conocía, Pepe Carrasco (lo encontraron con diez balas en el cuerpo). Ahora hablan de "la crueldad de la oposición, de esta gente de mente insana, degenerados", y los llaman "elementos", como si no alcanzaran a ser personas. Y hay que aguantar, mudos. Así es que en medio de estos acontecimientos, ¡no sabes la alegría que me da verte, querida Micaela! Repaso y saboreo los ratos que pasamos juntas. Te veo agitando tus manitos y diciendo "abo-abo" (¡bravo!) cuando pones tu carita en mi hombro y me abrazas. Gozaba regaloneando a mis hijos y ahora, a mis nietas. Criaturas que vinieron a endulzar los días que vivimos, ¡cuando tanta falta nos hace!

\section{Hacia el final}

Tras finalizado el libro, con Isidora seguimos manteniendo una amistad con encuentros y correspondencia. Vivió plenamente su vida, tal vez el último año se fue apagando, fue perdiendo algo de su locuacidad pero seguía escribiendo, teniendo proyectos en mente. Termino este tapiz de encuentros y experiencias, citando la carta que escribí a propósito de su muerte.

\section{Cuando una muerte puede ser la celebración de la vida} por Andrea Jeftanovic ${ }^{3}$

Isidora, a ti no te gustaba hablar de la muerte, decías que no querías morir porque te gustaba demasiado la vida. Pero al mismo tiempo, en tus obras dramáticas y en tus novelas los fantasmas andaban por acá y por allá; invocabas a Lautaro, a Bolívar, a Miranda, a los hermanos Sagredo de Ranquil, a los desaparecidos de Yumbel, a Neruda, a tu madre. Una vez esbozaste una definición de la muerte que apunté por ahí: "Puede ser que la muerte sea un desprenderse del dolor de la parte física y de todo lo que tú también mentalmente manejas y que ese sea un estado en que tú puedas sentirlo, gozarlo, no sé, nunca vamos 
a saber. Además yo pienso que si existe un Dios que nos creó, nos dejó esa incógnita para que no nos aburriéramos". En tus novelas especialmente encarabas la muerte, y también tus íntimas ilusiones, tus dolores y hablabas de los afectos muertos o de la muerte de los afectos. Ahora que atraviesas esa otra dimensión y descifras el misterio, no creo que te vayas a aburrir. Tendrás la oportunidad de abrazar a Laura Cupper y retomar las tertulias en la casona de la calle Rosas de Doy por vivido todo lo soñado. También podrás entregar por mano esa bella novela epistolar, Carta a Roque Dalton, dedicada al poeta salvadoreño. Los imagino caminando por el Malecón de La Habana contagiados por el entusiasmo de la meta de los diez millones de zafra que por ese entonces se prometía el pueblo cubano. Podrás curar una a una las heridas de la injusta muerte de Roque. También estarás con Jacobo, el protagonista de Santiago de diciembre a diciembre, esa historia durante el año de la campaña de Allende, cuando las parejas hacían el amor antes o después de leer el Manifiesto Comunista. Cuando la pasión tenía espesura y estaba enhebrada a alguna utopía. Quizás puedas detener la bala mortal de Balmaceda en Balmaceda, diálogos de amor y muerte y las voces corales sabrán encauzar la revolución sin tragedias. Pero también hay futuro. Verás en un mes publicada tu novela Guerreros del sur dedicada a un pueblo que necesita tanta fe en sus pacíficas batallas. Y tal vez, des los últimos ajustes a esa novela inédita, Palmira y Lorenzo, sobre esa relación de amor que ha atravesado los tiempos y las latitudes. Isidora o Palmira espera a Lorenzo o Tomás con lápices y pinceles y un gran lienzo.

Fuiste una dramaturga valiente, corajuda. No dudaste en ir a los basurales para entrevistar a los personajes que protagonizarían Los Papeleros, ni dejaste de conversar con las mujeres de las "tomas" para escribir Población Esperanza junto a Manuel Rojas, o de viajar en citroneta a Ranquil, cordillera adentro para escribir sobre la matanza de campesinos. Para Los que van quedando en el camino, fuiste con papel y lápiz a conversar con las pergoleras, viajaste a Yumbel para hacer esa obra que en medio de la dictadura denunciaba el horror de los detenidos desaparecidos ("Vivos los dejamos, vivos los queremos" en Retablo de Yumbel). Y también, viviste en una ruca mapuche con la familia Painemal para escribir Lautaro. Y podría seguir con cada una de tus obras. Ir a los lugares y hablar con los protagonistas era parte de tu riguroso método de investigación. Esa realidad se complementaba con acuciosas lecturas históricas, documentación diversa para quedar ensamblada en textos sagaces, bellamente escritos, que a 
veces incluían canciones y dichos populares. Y cuando no había protagonistas vivos los imaginaste, llamaste sus espíritus hasta tu habitación en la calle Rengo para que te susurraran ese secreto que no estaba escrito en los libros de historia. Eras la otra, la misma que contaba sin aspavientos que había tenido la oportunidad de conocer a Alejo Carpentier, el Che Guevara, Fidel Castro, Lezama Lima, Osvaldo Dragún, André Breton, J.L. Barrault, Gerard Philippe, Ionesco. La misma, la otra que odiaba que te saludaran con "es un honor conocerla" porque sabías que se referían al éxito de La Pérgola e ignoraban lo demás, porque eras tan lejana a esas formas protocolares, a la zalamería del poder. La misma a la que le dolía no haber recibido el Premio Nacional porque sabía que se lo merecía hace tiempo, la otra que seguía creando sin detenerse en la mediocridad de las instituciones y de algunos colegas. La que vivía en una ensoñación permanente, la otra que estaba siempre alerta.

Eras la misma, la otra que decía que era comunista pero que creía en Dios. La otra, la misma que con picardía infantil me chantajeaba con chocolates marca Trencito y pasteles (que se iba comiendo de a tercios) a cambio de contarme romances y anécdotas privadas que me hacías prometer no incluir en el libro que estábamos haciendo juntas. La que definitivamente amaba la noche y tenía horarios de adolescente (que no me llame nadie antes de mediodía, decías). Y si había panorama, la que no dudaba en ponerse su abrigo de piel y una capa de lápiz labial para hacernos reír hasta las lágrimas donde fuera con su cuento de la caperucita en veintinueve segundos cronometrados. La misma, la otra que no le gustaba que la fotografiaran pero que dejaba aflorar su coquetería cuando había un hombre cerca.

Prolífica en descendencia (hijos, nietos, bisnietos), en obra y en amores eras la más joven de todas, la más desprejuiciada, la más ingeniosa, la más seductora, la que tenía un pasado fascinante y un futuro con varios proyectos. Además, tenías un don en tu escritura y en tu contacto con la gente, irradiabas y multiplicabas cosas positivas, redes, sueños.

La académica española Carmen Márquez, dice que eras una excelente celestina que unías a personas a las que querías con lazos casi familiares. Un amigo y colega, Nelsón Osorio, escribe:

“Nuestro país, las letras y la cultura de nuestra América pierden con su partida una de las figuras más nobles e íntegras de nuestra época. Nos queda su obra, notable y valiosa, y su ejemplo de consecuencia, integridad y valor." 
Otra amiga y escritora, Virginia Vidal, dice:

"Isidora nos dio tanta vida, tanta dicha, tanto ejemplo, tanta consecuencia, tanta generosidad que algo de ella se queda en cada una de nosotras. Desfilan ante mí escenas de innumerables encuentros. Cuando murió Roberto Bolaño, Nicanor Parra dijo: "le debemos un hígado". A Isidora, Chile la entierra debiéndole el Premio Nacional de Literatura que habría sido menguado reconocimiento a su vasta obra de novelista y dramaturga". Yo misma tendré que releer con calma nuestra abundante correspondencia, o escuchar las cintas de audio de nuestras extensas pláticas; horas, días, meses, años charlando una frente a la otra."

Isidora o Nené, la otra, la misma; guardiana de la historia, la amistad, el teatro y las letras, tu despedida fue como tu vida: una celebración. Tus casi 92 años de existencia se despidieron con lecturas, actuaciones, videos, música; cuando el ataúd se cerró éramos muchos aplaudiendo de pie en el Teatro Nacional Antonio Varas. Luego bajo el sol de una tarde de febrero caminó una descendencia familiar infinita, colegas, amigos de diversas generaciones, admiradores, camaradas, se alternaban los "Compañera Isidora, presente" con los "¿Quiere flores señorita, quiere flores el señor?" y la canción de Manuel Rodríguez, "aunque mil veces te maten/tu huella queda encendida", para avanzar entre la ofrenda de pétalos de las pergoleras en Avenida La Paz. Nos seguía el equipo que está haciendo el documental sobre tu vida y obra que estoy segura filmaron todo con la vista empañada.

De pronto miramos y estaban las tres generaciones de "Carmelas" abrazadas: las actrices Carmen Barros, Marcela Medel y Ema Pinto. Por supuesto que hubo lágrimas, la sensación de corte, la intuición de un vacío que se aproxima. Pero también una muerte así es en un punto una celebración de lo que puede ser la vida, la vida de una artista excepcional e imprescindible. 
Andrea Jeftanovic - Homenaje a Isidora Aguirre (1919-2011)...

\section{Notas}

1 Jeftanovic, Andrea. Conversaciones con Isidora Aguirre. Santiago de Chile: Ediciones Frontera Sur, 2009.

2 Fragmentos de diarios personales de distintos momentos de su vida. Material inédito.

3 Carta publicada en los sitios digitales Clarin.cl, La ventana (Casa de las Américas, Cuba), Letras de Chile y Ojo literario. 